\title{
Inheritance of Phytophthora root rot resistance in red raspberry determined by generation means and molecular linkage analysis
}

\author{
Jeremy A. Pattison · Suren K. Samuelian • \\ Courtney A. Weber
}

Received: 22 November 2006 / Accepted: 11 April 2007 / Published online: 22 May 2007

(C) Springer-Verlag 2007

\begin{abstract}
Classical and molecular methodologies were used to determine the inheritance of Phytophthora root rot (PRR) resistance in red raspberry. The varieties 'Latham' and 'Titan,' resistant and susceptible, respectively, were used to create $\mathrm{F}_{1}, \mathrm{~F}_{2}, \mathrm{~B}_{1}, \mathrm{~B}_{2}$, and $\mathrm{S}_{1}$ populations for analysis. Generational means analysis was used to calculate the components of genetic variation and estimates of narrow and broad sense heritability for the plant disease index and the incidence of petiole lesions. The plant disease index showed additive genetic variation with additional significant interactions, but the incidence of petiole lesions was non-additive. A dominant, two-gene model was shown to be the best fit for the observed segregation ratios when classification for resistance was based on a combination of all criteria measured. Molecular linkage maps were generated from the segregating $B_{2}$ population. Linkage maps of both parents were constructed from amplified fragment length polymorphism (AFLP), Random amplified polymorphic DNA (RAPD), and uncharacterized resistant gene analog polymorphism (RGAP) markers with seven linkage groups each totaling 440 and $370 \mathrm{cM}$ of genetic distance, respectively. An analysis of the distributional extremes of the $\mathrm{B}_{2}$ population identified several RAPD markers clustered on
\end{abstract}

Communicated by H. Nybom.

\section{J. A. Pattison}

Virginia Polytechnic Institute and State University,

Southern Piedmont Agricultural Research and Extension Center,

2375 Darvills Road, Blackstone, VA 23824, USA

S. K. Samuelian · C. A. Weber $(\square)$

Department of Horticultural Sciences,

New York State Agricultural Experiment Station,

Cornell University, Geneva, NY 14456, USA

e-mail: caw34@nysaes.cornell.edu two linkage groups associated with PRR resistance. QTL analysis identified two similar genomic regions on each map that explained significant percentages of phenotypic variation observed for the disease assessment criteria. Genetic mapping supports the dominant two-gene model developed from generational means analysis. The results reconcile conflicting reports on inheritance of PRR resistance, provide a basis for further investigation of durable resistance to Phytophthora caused diseases, and indicates that recurrent selection is the appropriate approach for the development of new resistant cultivars.

\section{Introduction}

Root rot in red raspberries, caused by Phytophthora fragariae var. rubi Wilcox and Duncan, reduces crop productivity and is a major production constraint in all raspberrygrowing regions of the world (Wilcox et al. 1993; Wilcox and Latorre 2002). An integrative management approach utilizing resistant cultivars, registered fungicides, and avoidance or amelioration of wet soils to reduce the effects of the disease is recommended for control (Wilcox et al. 1999; Heiberg 1995; Maloney et al. 1993). Typical symptoms include severe root rot, leaf chlorosis, stem and petiole lesions and necrosis, and wilting (Wilcox 1989).

Resistance to Phytophthora root rot (PRR) is found particularly in cultivars derived from Rubus idaeus strigosus Michx., the native North American red raspberry and less so in those derived from $R$. idaeus vulgatus Arrhen., the native European red raspberry (Bristow et al. 1988; Daubeny and Anderson 1993; Knight 1991; Levesque and Daubeny 1999; Pattison and Weber 2005). Nestby and Heiberg (1995) found that several cultivars, including 'Asker' which is of European origin, could confer resistance to 
some progeny populations. Other early products of North American breeding programs such as 'Latham,' 'Newburgh,' 'Durham,' and 'Chief' are also highly resistant to PRR (Barritt et al. 1981) and have been used as parents to produce newer resistant varieties (Nestby and Heiberg 1995). Studies to date have not determined if the same genes control the North American and the European source for resistance. More productive cultivars with improved fruit quality have dominated the recent market, but many are susceptible to PRR (Pattison and Weber 2005).

Inheritance in a parent-offspring regression study of field screened progenies showed that resistance to PRR is heritable with considerable additive genetic variation and that moderate progress toward resistance could be achieved through recurrent selection (Barritt et al. 1979). However, Nestby and Heiberg (1995) concluded that resistance is more influenced by non-additive genetic variation (i.e., dominance and epistasis) and/or environmental effects and calculated low estimates of narrow sense heritability and thus a poor prospect for recurrent genetic improvement. The experimental conditions were quite different between the two studies and direct comparisons of data are not appropriate as heritability is population specific. Nevertheless, these studies reveal that resistance to PRR is heritable and may be conditioned by major genetic factors. However, there is no consensus for the mode of inheritance for resistance to PRR or for the most appropriate approach to breeding cultivars with improved resistance.

Molecular linkage maps have been constructed for many agricultural crop species (Collins et al. 1998; Graham et al. 2004; Kanazin et al. 1996; Liebhard et al. 2003; Sargent et al. 2004) with a diversity of marker types providing researchers flexibility in choosing the most appropriate system for the crop species of interest based on available sequence information and specific study objectives. Random amplified polymorphic DNA (RAPD) and amplified fragment length polymorphisms (AFLPs) are frequently used in generating molecular linkage maps because they require no host genome sequence information, can produce moderate to high levels of polymorphisms, and are technically simple and very cost effective for the amount of information gained relative to the time and money invested.

Other marker systems are available but require sequence information specific to the target crop's genome. There is, however, much conservation among certain classes of genes with disease resistant genes in particular showing shared sequence motifs across a wide range of host plants and pathogens. Leister et al. (1996) designed degenerate primers based on the conserved LRR (leucine rich repeat) regions of RPS2 from Arabidopsis thaliana L. and the $N$ gene of tobacco (Nicotiana tabacum L). Amplification products obtained from potato (Solanum tuberosum L.) were shown to be homologous to known resistance genes and linked to the nematode resistance gene Grol and the late blight resistance locus $R 7$ (Leister et al. 1996). Chen et al. (1998) used degenerate and specific primers designed from conserved motifs of $\mathrm{R}$ genes targeted to bacteria, fungi, and viruses, and found that many amplification products could be resolved using polyacrylamide gel electrophoresis. They proposed that this method could be useful for generating markers linked to disease resistance loci. This conserved marker approach has been used to isolate and characterize resistant gene analog polymorphisms (RGAPs) linked to disease resistance traits in cassava (Manihot esculenta Crantz) (Lopez et al. 2003), citrus (Citrus grandis Osbeck. $x$ Poncirus trifoliata Raf. hybrid) (Deng et al. 2000), grape (Vitis vinifera L.) (Di Gaspero and Cipriani 2002, 2003), lettuce (Lactuca spp.) (Shen et al. 1998), maize (Zea mays L.) (Collins et al. 1998), and soybean (Glycine max Merr.) (Kanazin et al. 1996).

The objectives of this study were to determine the mode of inheritance of resistance to PRR, develop a molecular genetic linkage map to identify markers associated with the resistant phenotype, and test the usefulness of degenerate primers designed from conserved disease resistant gene motifs for producing markers linked to PRR resistance.

\section{Materials and methods}

Plant material

A single PRR resistant $F_{1}$ individual, NY00-34 ('Titan' $\times$ 'Latham') (Maloney 2001), was used as the female parent to generate $B_{1}, B_{2}$, and $F_{2}$ populations. These populations, an additional $F_{1}$ population and the $S_{2}$ population were screened for PRR resistance (Pattison et al. 2004) as well as replicated clones of 'Latham,' 'Titan' and NY0034 (Table 1) using the method described by Pattison et al. (2004). Tissue culture plugs were used for screening clonal material of 'Latham' and 'Titan' and root cuttings for NY00-34.

Disease screening and assessment

The root systems of seedling plants with two to four true leaves were washed free of planting media and soaked in a dilute solution of antibacterial soap for $15 \mathrm{~min}$ and then transplanted into a hydroponic basin as described by Pattison et al. (2004). The seedlings' crowns were placed into a rock wool cube and placed into planting holes evenly distributed across the lid of the hydroponic basin. The roots were submerged and grown with aeration in half strength Peter's Professional Hydro-Sol 5-11-26 nutrient solution (W.R. Grace \& Co., Fogelsville, PA), supplemented with $10 \mathrm{mM} \mathrm{Ca}\left(\mathrm{NO}_{3}\right)_{2}$. The volume was maintained by adding 
Table 1 Goodness of fit analysis for the proposed inheritance model based on the observed segregation ratios of the $\mathrm{P}_{1}, \mathrm{P}_{2}$, $\mathrm{P}_{3}, \mathrm{~F}_{1}, \mathrm{~F}_{2}, \mathrm{~B}_{1}, \mathrm{~B}_{2}$, and $\mathrm{S}_{2}$ generations after exposure to Phytophthora fragariae var. rubi

${ }^{\text {a }}$ Chi-square value was calculated using the Yates correction factor for small expected class sizes (Strickberger 1985)

\begin{tabular}{|c|c|c|c|c|c|c|c|c|c|}
\hline \multirow[t]{2}{*}{ Cross/genotype } & \multirow[t]{2}{*}{ Code } & \multirow[t]{2}{*}{$n$} & \multirow[t]{2}{*}{ Mean } & \multicolumn{2}{|c|}{ Observed } & \multicolumn{2}{|c|}{ Expected } & \multirow[t]{2}{*}{$\chi^{2}$} & \multirow[t]{2}{*}{$P$} \\
\hline & & & & $R$ & $S$ & $R$ & $S$ & & \\
\hline Latham & $\mathrm{P}_{1}$ & 18 & 1.50 & 18 & 0 & - & - & - & - \\
\hline Titan & $\mathrm{P}_{2}$ & 18 & 4.73 & 0 & 18 & - & - & - & - \\
\hline Latham $\times$ Titan & $\mathrm{F}_{1}$ & 51 & 3.00 & 29 & 22 & 1 & 1 & 0.96 & 0.35 \\
\hline NY00-34 & $\mathrm{P}_{3}$ & 18 & 1.67 & 18 & 0 & - & - & - & - \\
\hline NY00-34 ${ }^{\otimes}$ & $\mathrm{F}_{2}$ & 80 & 3.36 & 44 & 36 & 9 & 7 & 0.05 & 0.84 \\
\hline NY00-34 × Latham & $\mathrm{B}_{1}$ & 50 & 1.74 & 50 & 0 & 3 & 1 & $15.36^{\mathrm{a}}$ & $<0.001$ \\
\hline NY00-34 × Titan & $\mathrm{B}_{2}$ & 159 & 3.85 & 52 & 107 & 3 & 5 & 1.52 & 0.23 \\
\hline $\operatorname{Titan}^{\otimes}$ & $\mathrm{S}_{2}$ & 30 & 4.77 & 0 & 30 & - & - & - & - \\
\hline
\end{tabular}

nutrient solution to the basin and the $\mathrm{pH}$ was adjusted to 6.5. The basins were kept in a growth chamber with 14-h days at $20^{\circ} \mathrm{C}$. Tissue culture plug plants of the resistant ('Latham') and susceptible ('Titan') parents were included as controls in all hydroponic basins.

Inoculation of the basins was done with two pathogenic isolates of P. fragariae var. rubi, ATCC 16184 (M14) and NY588. Inoculum was produced by growing the isolates separately in clarified V-8 broth for 14-21 days as described by Bristow et al. (1988). Mycelium was collected using a Buchner funnel and $2 \mathrm{~g}$ of each isolate were placed in $500 \mathrm{ml}$ of filter sterilized deionized water and fragmented in a blender for two consecutive 5-s pulses. Each hydroponic basin was inoculated with the mycelial suspension when plants reached $15-20 \mathrm{~cm}$ in height. Aeration was withheld for $48 \mathrm{~h}$ after inoculation. The nutrient solution was sampled weekly for the presence of zoospores by transferring $5 \mathrm{ml}$ aliquots into $15 \mathrm{ml}$ centrifuge tubes, vortexing for $1 \mathrm{~min}$ and examined in a hemocytometer under the microscope. Disease screening and assessments were performed at 30-40 days post-inoculation as previously described (Pattison et al. 2004) and consisted of a plant disease index (Table 2), a root regeneration score (Table 3), stem lesion length, and the percent incidence of petiole lesions.

Table 2 Plant disease index for assessing the susceptibility of red raspberry genotypes following inoculation with Phytophthora fragariae var. rubi

\begin{tabular}{ll}
\hline Score & Symptoms \\
\hline 1 & Slight root rot. No shoot symptoms \\
2 & Slight root rot. Slight shoot symptoms \\
3 & Moderate root rot. Moderate shoot symptoms \\
4 & Severe root rot. Severe shoot \\
5 & symptoms with living crown tissue \\
\hline
\end{tabular}

Table 3 Root regeneration score for assessing susceptibility of red raspberry genotypes following inoculation with Phytophthora fragariae var. rubi

\begin{tabular}{ll}
\hline Score & Symptoms \\
\hline 0 & No new root tissue. Old roots and crown necrotic \\
1 & $\begin{array}{c}\text { Healthy crown and older root tissue with little } \\
\text { to no new root tissue }\end{array}$ \\
2 & $\begin{array}{l}\text { Healthy crown and older root tissue with } \\
\text { moderate new root production }\end{array}$ \\
3 & $\begin{array}{c}\text { Healthy crown and older root tissue with } \\
\text { vigorous new root production }\end{array}$ \\
\hline
\end{tabular}

Inheritance analysis

Chi-square distributions were used to test goodness-of-fit for proposed inheritance models. The components of genetic variation for the plant disease index and incidence of petiole lesions were calculated using generation means analysis according to Mather and Jinks (1982) based on the means and standard errors of the three clonal parents and four populations $\left(\mathrm{F}_{1}, \mathrm{~F}_{2}, \mathrm{~B}_{1}\right.$, and $\left.\mathrm{B}_{2}\right)$. The analysis was performed using a spreadsheet program ( $\mathrm{Ng}$ 1990) that estimated broad sense $\left(H^{2}\right)$ (Allard 1960) and narrow sense $\left(h^{2}\right)$ (Warner 1952) heritability. The adequacy of the additive-dominance model was evaluated by using a joint scaling procedure, which uses weighted least squares estimates based on the generation means (Cavalli 1952) and tested for fit using a chi-square distribution. Lack of fit suggests the presence of non-additive gene effects other than dominance such as, additive $\times$ additive, additive $\times$ dominance and/or dominance $x$ dominance. In such instances, further analysis can be performed to determine which interactions are significant using a $t$-test.

Separate goodness-of-fit tests were also performed using simple inheritance models to test the hypothesis that the action of a few genes is involved in PRR resistance in red raspberry. For this analysis a forced classification of individuals was 
done where all individuals that maintained crown and older root tissue free from necrosis (plant disease index values of 1 , 2 , or 3) were classified as resistant genotypes and those in which the disease moved into the crown (plant disease index scores of 4 or 5) were classified as susceptible. Multiple permutations were tested for fit including a single dominantrecessive gene model up to a three-gene model.

\section{Marker generation}

Newly expanded leaf tissue was collected from the $\mathrm{B}_{2}$ population and parents and DNA isolated as described by Lodhi et al. (1994) for all PCR procedures. AFLP markers were generated using the procedure of Vos et al. (1995) with small modifications. All adapters and primers were obtained from MWG-Biotech, Ebersberg, Germany. Digestions, ligations, and amplifications were performed on a PTC-100 thermocycler (MJ Research, Watertown, MA) with a heated lid. DNA template was prepared by digesting 200-300 ng genomic DNA with $2 \mathrm{U}$ each of EcoRI and MseI restriction enzyme in a final volume of $40 \mu \mathrm{l}$ for $2 \mathrm{~h}$ at $37^{\circ} \mathrm{C}$ following the manufactures directions (NEB, Beverly, MA). Next, $15 \mu \mathrm{l}$ of a solution containing $5 \mathrm{pM}$ EcoRI adapter (EcoRI_ad1 CTCGTAGACTGCGTACC and EcoRI_ad2 AATTGGTACGCAGTC) and $50 \mathrm{pM}$ MseI adapter (MseI_ad1 GACGATGAGTCCTGAG and MseI_Ad2 TACTCAGGACTCAT), $1 \mathrm{U}$ T4 Ligase (NEB) and $3.7 \times$ NEB Ligase buffer were added, and the ligation was performed at $37^{\circ} \mathrm{C}$ for $2 \mathrm{~h}$. The same procedure was performed to generate EcoRI/Pst I template using 5 pM EcoRI adapter and 5 pM PstI adapter (PstI_ad1 CTCGTAGACTGCGTACATGCA and PstI_ad2 TGTACGCAGTCTAC).

Pre-amplification was conducted with no selective nucleotides (EcoRI + 0-GACTGCGTACCAATTC, MseI + 0 -GATGAGTCCTGAGTAA, and Pst +0 -GACTGC GTACATGCAG) followed by amplification with two selective nucleotides. Amplification with three selective nucleotides was preceded by pre-amplification with one selective nucleotide, e.g., $M s e \mathrm{I}+\mathrm{C}$ and $M s e \mathrm{I}+\mathrm{G}$. Preamplification was carried out with $4 \mu \mathrm{l}$ of tenfold-diluted ligated template, $49.3 \mathrm{mM}$ Tris-HCL ( $\mathrm{pH} 8.3), 2.5 \mathrm{mM}$ $\mathrm{MgCl}_{2}, 1 \mathrm{mM}$ tartrazine, $1.5 \%$ ficoll, $125 \mu \mathrm{M}$ of each dNTP, 20 pmol each primer, and 1 U Taq DNA polymerase in a final volume of $40 \mu \mathrm{l}$. Primer combinations $E c o \mathrm{RI}+\mathrm{NN}^{\prime} / M s e \mathrm{I}+\mathrm{NN}^{\prime}, \quad E c o \mathrm{RI}+\mathrm{NN}^{\prime} / M s e \mathrm{I}+\mathrm{NN}^{\prime} \mathrm{N}^{\prime \prime}$, $E c o \mathrm{RI}+\mathrm{N} / P s t \mathrm{I}+\mathrm{N}, E c o \mathrm{RI}+\mathrm{NN}^{\prime} / P s t \mathrm{I}+\mathrm{N}$, and $E c o \mathrm{RI}+$ $\mathrm{NN}^{\prime} /$ Pst $\mathrm{I}+\mathrm{NN}^{\prime}$, where $\mathrm{N}$ are the selective nucleotides, were analyzed in order to find the optimum number of selective nucleotides that would generate clearly scorable AFLP fragments. Amplifications were performed with tenfold-diluted pre-amplification mixture as template.

Optimal separation of AFLP fragments was achieved with the primer combinations $E c o \mathrm{RI}+\mathrm{NN}^{\prime} / M s e \mathrm{I}+\mathrm{NN}^{\prime} \mathrm{N}^{\prime \prime}$ and $E c o \mathrm{RI}+\mathrm{NN}^{\prime} / P s t \mathrm{I}+\mathrm{NN}^{\prime}$, which were further used in this study. After diluting the amplification products $1: 1$ with Stop/Loading buffer (Li-Cor, Lincoln, NE), the AFLP fragments were denatured at $94^{\circ} \mathrm{C}$ for $3 \mathrm{~min}$ and separated by electrophoresis through $6.5 \%$ denaturing polyacrylamide gel (Gel Matrix, Li-Cor) on a LI-COR Gene ReadIR 4200 automated DNA sequencing system (Li-Cor). Visualization of the fragments was achieved by end labeling of the EcoRI primers with IR800 dye. Calculation of the DNA sizes was performed based on 50-700 Size-Standard IR800 Dye (Li-Cor). The AFLP markers were labeled according to the Standard List for AFLP Primer Nomenclature (http:// www.wheat.pw.usda.gov/ggpages/keygeneAFLPs.html). For example, marker EcoRI + CC/MseI + CTA with a size of 366 bp is labeled as E16M59_366.

DNA amplification for RAPD marker generation was based on the procedure of Cai et al. (1994). PCR reactions were done in a total volume of $25 \mu$ containing $49.3 \mathrm{mM}$ Tris-HCL (pH 8.3), $2.5 \mathrm{mM} \mathrm{MgCl}_{2}, 1 \mathrm{mM}$ tartrazine, $1.5 \%$ ficoll, $125 \mu \mathrm{M}$ of each dNTP, $0.4 \mu \mathrm{M}$ primer, $1 \mathrm{U}$ Taq polymerase, and $60 \mathrm{ng}$ of genomic DNA. DNA was amplified in a MJ Research PTC-100 thermocycler with a heated lid for 45 cycles. Each cycle was programmed for $1 \mathrm{~min}$ at $94^{\circ} \mathrm{C}$, $1.5 \mathrm{~min}$ at $35^{\circ} \mathrm{C}, 2 \mathrm{~min}$ at $72^{\circ} \mathrm{C}$, followed by a 6 min extension at $72^{\circ} \mathrm{C}$ at the end of the last cycle before cooling to $6^{\circ} \mathrm{C}$. Amplified DNA fragments were separated on a $2 \%$ TAE agarose gel and visualized by ethidium bromide staining. RAPD marker nomenclature is as follows: the first letters designate primer origin $(\mathrm{BC}=$ University of British Columbia, Vancouver, BC, Canada; OP = Operon Technologies, Alameda, CA). The next three numbers indicate the primer number followed by three numbers indicating the fragment size in base pairs.

The RGAP reactions were done with the same procedure as for RAPDs with the following modifications. In each reaction, $0.4 \mu \mathrm{M}$ of both a forward and reverse primer was added. Each cycle was programmed for $1 \mathrm{~min}$ at $94^{\circ} \mathrm{C}$, $1 \mathrm{~min}$ at $45^{\circ} \mathrm{C}, 2 \mathrm{~min}$ at $72^{\circ} \mathrm{C}$, followed by a 6 min extension at $72^{\circ} \mathrm{C}$ at the end of the last cycle before cooling to $6^{\circ} \mathrm{C}$. Amplified DNA fragments were separated on a 2.5$3 \%$ TAE Metaphor ${ }^{\mathrm{TM}}$ agarose gel (BioWhittaker Molecular Applications, Rockland, ME) and visualized by ethidium bromide staining. Sequence specific primers designed from conserved motifs of resistance genes (Chen et al. 1998) were used to amplify resistant gene like sequences (Table 4). A total of 79 primer combinations were tested on the parents and combinations that produced polymorphisms were used on the mapping population.

\section{Analysis of distributional extremes}

Based on the theory used in bulked segregant analysis, individuals from the distributional extremes of the $B_{2}$ population 
Table 4 Sequences of the primers used to amplify resistance gene analogs (RGAs) in red raspberry designed from conserved domains of resistance genes from multiple species

\begin{tabular}{llll}
\hline Primer & Sequence $\left(5^{\prime}-3^{\prime}\right)$ & R gene $/$ domain & References \\
\hline PtoKin 1 & GCATTGGACAAGGTGAA & Pto/protein kinase & Chen et al. (1998) \\
PtoKin 2 & AGGGGGACCACCACGTAG & RPS2 and N/P-loop & Leister et al. (1996) \\
AS1 & CAACGCTAGTGGCAATCC & RPS2/LRR & Chen et al. (1998) \\
RLRR-f & CGCAACCACTAGAGTAAC & & Chen et al. (1998) \\
RLRR-r & ACACTGGTCCATGAGGTT & Xa21/LRR & Chen et al. (1998) \\
XLRR-f & CCGTTGGACAGGAAGGAG & N/LRR & Chen et al. (1998) \\
XLRR-r & CCCATAGACCGGACTGTT & & Cf9/LRR \\
NLRR-f & TAGGGCCTCTTGCATCGT & & Yu et al. (1996) \\
NLRR-r & TATAAAAAGTGCCGGACT & RPS2 and N/P-loop and Kinase 3a & \\
CLRR-r & TTTTCGTGTTCAACGACG & & \\
NBS-F1 & TAACGTCTATCGACTTCT & & \\
NBS-R1 & YCTAGTTGTRAYDATDAYYYTRC & & \\
\hline
\end{tabular}

a Pto and RPS2 genes from tomato and Arabidopsis, respectively, confer resistance against Pseudomonas syringae pv. tomato. The $N$ gene from tobacco confers resistance against tobacco mosaic virus. The $C f 9$ gene from tomato confers resistance against Cladosporium fulvum. The Xa21 gene from rice confers resistance against Xanthomonas campestris pv. Oryzae

were analyzed for significant interactions with specific RAPD markers. DNA from nine resistant and susceptible phenotypes from the distributional extremes of the population was analyzed separately with each RAPD primer instead of as pooled DNA samples used for bulked segregant analysis. The nine resistant individuals had a plant disease index score of 1 or 2 and the nine susceptible plants had a plant disease index score of 5. A total of 225 RAPD primers were screened for polymorphisms between the two groups of individuals. These primers were previously shown to produce amplified products in an unrelated raspberry population (data not shown). Each primer that produced a significantly linked fragment, as determined by a $t$-test at $\alpha=0.05$, was used on the 68 individuals of the mapping population to determine map location of linked markers.

Molecular genetic mapping and QTL analysis

Identified polymorphisms were scored in the mapping population and mapped using JoinMap 3.0 ${ }^{\circledR}$ (Van Oijen and Voorips 2001). The population design and high level of polymorphism in red raspberry allowed for the development of separate parental linkage maps. Each map contained both heterozygous markers (present in both parents and segregating $3: 1$ in the population) and backcross markers (present/heterozygous in one parent and homozygous recessive/absent in the other and segregating 1:1 in the population). Markers deviating significantly from expected segregation ratios were removed from the data set after observing many to be unlinked or clustering to a separate small linkage group (data not shown). Linkage groups were assigned using a LOD score of 5.0.

QTL analysis was performed using MapQTL $4.0^{\circledR}$ (Van Oijen et al. 2002). LOD thresholds were calculated by permutation analysis for each trait and linkage group individually. Kruskal-Wallis analysis was used to detect markers linked to the phenotypic data and significant QTL were declared by interval mapping when the sample data exceeded the LOD threshold.

\section{Results}

Clonally replicated plants of 'Latham' and 'Titan' displayed the resistant and susceptible phenotype, respectively, when exposed to $P$. fragariae var. rubi using the hydroponic system (Pattison et al. 2004), and NY00-34 was classified as resistant as 'Latham' based on all assessment criteria (Tables 5, 6, 7, 8). The $F_{1}$ and $F_{2}$ populations segregated widely for all assessment criteria with recovery of both parental phenotypes except for stem lesion length, which did not reach the size observed in 'Titan' and was skewed toward no lesions (Tables 5, 6, 7, 8). Little segregation was observed in the $B_{1}$ population for all resistance measurements with no individuals expressing susceptibility similar to the susceptible parent, 'Titan' (Tables 5, 6, 7, 8). The $\mathrm{B}_{2}$ population generated segregants of both parental phenotypes for all traits except stem lesion length again where the severity of 'Titan' was not observed (Tables 5, 6, 7, 8).

Simple segregation for the presence of stem lesions was observed where individuals with low plant disease index 
Table 5 Relative frequency distributions (percentage) of plant disease index scores in parental clones and red raspberry populations segregating for resistance to root rot caused by Phytophthora fragariae var. rubi

\begin{tabular}{|c|c|c|c|c|c|c|c|c|}
\hline \multirow[t]{2}{*}{ Genotype/population } & \multirow[t]{2}{*}{ Family } & \multirow[t]{2}{*}{$n$} & \multicolumn{5}{|c|}{ Plant disease index score } & \multirow[t]{2}{*}{ Mean \pm SE } \\
\hline & & & 1 & 2 & 3 & 4 & 5 & \\
\hline Latham & $\mathrm{P} 1$ & 18 & 44 & 56 & 0 & 0 & 0 & $1.50 \pm 0.11$ \\
\hline Titan & P2 & 18 & 0 & 0 & 0 & 28 & 72 & $4.72 \pm 0.11$ \\
\hline NY00-34 & $\mathrm{P} 3$ & 18 & 33 & 67 & 0 & 0 & 0 & $1.67 \pm 0.11$ \\
\hline Latham $\times$ Titan & $\mathrm{F}_{1}$ & 51 & 20 & 24 & 14 & 24 & 20 & $3.0 \pm 0.20$ \\
\hline NY00-34 × NY00-34 & $\mathrm{F}_{2}$ & 80 & 9 & 19 & 27 & 17 & 27 & $3.36 \pm 0.15$ \\
\hline Latham $\times$ NY00-34 & $\mathrm{B}_{1}$ & 50 & 38 & 50 & 12 & 0 & 0 & $1.74 \pm 0.09$ \\
\hline Titan $\times$ NY00-34 & $\mathrm{B}_{2}$ & 159 & 6 & 11 & 16 & 26 & 41 & $3.85 \pm 0.10$ \\
\hline Titan $\times$ Titan & $\mathrm{S}_{2}$ & 30 & 0 & 0 & 3 & 17 & 80 & $4.77 \pm 0.09$ \\
\hline
\end{tabular}

\begin{tabular}{|c|c|c|c|c|c|c|c|}
\hline \multirow[t]{2}{*}{ Genotype/population } & \multirow[t]{2}{*}{ Family } & \multirow[t]{2}{*}{$n$} & \multicolumn{4}{|c|}{ Root regeneration score } & \multirow[t]{2}{*}{ Mean $\pm \mathrm{SE}$} \\
\hline & & & 0 & 1 & 2 & 3 & \\
\hline Latham & $\mathrm{P} 1$ & 18 & 0 & 0 & 67 & 33 & $2.33 \pm 0.11$ \\
\hline Titan & $\mathrm{P} 2$ & 18 & 100 & 0 & 0 & 0 & 0 \\
\hline NY00-34 & $\mathrm{P} 3$ & 18 & 0 & 0 & 50 & 50 & $2.50 \pm 0.12$ \\
\hline Latham $\times$ Titan & $\mathrm{F}_{1}$ & 51 & 43 & 16 & 29 & 12 & $1.10 \pm 0.15$ \\
\hline NY00-34 × NY00-34 & $\mathrm{F}_{2}$ & 80 & 44 & 34 & 19 & 4 & $0.83 \pm 0.10$ \\
\hline Latham $\times$ NY00-34 & $\mathrm{B}_{1}$ & 50 & 0 & 20 & 60 & 20 & $2.00 \pm 0.10$ \\
\hline Titan $\times$ NY00-34 & $\mathrm{B}_{2}$ & 159 & 67 & 18 & 11 & 5 & $0.54 \pm 0.07$ \\
\hline Titan $\times$ Titan & $\mathrm{S}_{2}$ & 30 & 100 & 0 & 0 & 0 & 0 \\
\hline
\end{tabular}

Table 6 Relative frequency distributions (percentage) of root regeneration scores in parental clones and red raspberry populations segregating for resistance to root rot caused by Phytophthora fragariae var. rubi

Table 7 Relative frequency distributions (percentage) of stem lesion length in parental clones and red raspberry populations segregating for resistance to root rot caused by Phytophthora fragariae var. rubi

\begin{tabular}{|c|c|c|c|c|c|c|c|c|c|c|c|c|c|c|c|c|c|c|c|}
\hline \multirow[t]{2}{*}{ Genotype/population } & \multirow[t]{2}{*}{ Family } & \multirow[t]{2}{*}{$n$} & \multicolumn{16}{|c|}{ Stem lesion size $(\mathrm{cm})$} & \multirow[t]{2}{*}{ Mean \pm SE } \\
\hline & & & 0 & 1 & 2 & 3 & 4 & 5 & 6 & 7 & 8 & 9 & 10 & 11 & 12 & 13 & 14 & 15 & \\
\hline Latham & P1 & 18 & 100 & 0 & 0 & 0 & 0 & 0 & 0 & 0 & 0 & 0 & 0 & 0 & 0 & 0 & 0 & 0 & 0 \\
\hline Titan & $\mathrm{P} 2$ & 18 & 0 & 0 & 0 & 0 & 0 & 11 & 11 & 6 & 6 & 17 & 11 & 6 & 0 & 11 & 17 & 6 & $9.83 \pm 0.80$ \\
\hline NY00-34 & P3 & 18 & 100 & 0 & 0 & 0 & 0 & 0 & 0 & 0 & 0 & 0 & 0 & 0 & 0 & 0 & 0 & 0 & 0 \\
\hline Latham $\times$ Titan & $\mathrm{F}_{1}$ & 51 & 69 & 6 & 10 & 0 & 4 & 4 & 2 & 4 & 2 & 0 & 0 & 0 & 0 & 0 & 0 & 0 & $1.13 \pm 0.30$ \\
\hline NY00-34 × NY00-34 & $\mathrm{F}_{2}$ & 80 & 70 & 10 & 0 & 4 & 5 & 1 & 1 & 0 & 3 & 1 & 5 & 0 & 0 & 0 & 0 & 0 & $1.36 \pm 0.31$ \\
\hline Latham $\times$ NY00-34 & $\mathrm{B}_{1}$ & 50 & 100 & 0 & 0 & 0 & 0 & 0 & 0 & 0 & 0 & 0 & 0 & 0 & 0 & 0 & 0 & 0 & 0 \\
\hline Titan $\times$ NY00-34 & $\mathrm{B}_{2}$ & 159 & 48 & 8 & 6 & 7 & 4 & 9 & 6 & 3 & 1 & 4 & 2 & 0 & 0 & 0 & 0 & 1 & $2.35 \pm 0.24$ \\
\hline Titan $\times$ Titan & $\mathrm{S}_{2}$ & 30 & 10 & 17 & 7 & 7 & 3 & 0 & 7 & 3 & 7 & 3 & 10 & 0 & 3 & 0 & 0 & 20 & $7.17 \pm 1.09$ \\
\hline
\end{tabular}

( $\leq 3)$ scores had no stem lesions (Tables 5, 8). However, plants with high plant disease index scores $(\geq 4)$ did not always display a stem lesion, despite severe symptom expression for all other traits. The incidence of petiole lesions exhibited complex segregation with both parental phenotypes identified in all generations except $B_{1}$ where individuals with no petiole lesions were not observed (Table 8).

Generational means analysis of the plant disease index revealed that the additive-dominance model could not ade- quately account for all of the variation observed in these populations as indicated by the joint scaling test $\left[\chi^{2}\right.$ $(d f=3)=30.303, P<0.001]$. Additional analysis revealed significant additive $\times$ additive, additive $\times$ dominance and dominance $\times$ dominance interactions. However the additive variance was the largest component of the total variance, producing high narrow and broad sense heritability estimates of $h^{2}=0.86$ and $H^{2}=0.88$, respectively.

Most of the variance in the incidence of petiole lesions was observed to be dominant with little additive genetic 
Table 8 Relative frequency distributions (percentage) of the frequency of the incidence of petiole lesions in parental clones and red raspberry populations segregating for resistance to root rot caused by Phytophthora fragariae var. rubi

\begin{tabular}{|c|c|c|c|c|c|c|c|c|c|c|c|c|c|c|}
\hline \multirow[t]{2}{*}{ Genoytpe/population } & \multirow[t]{2}{*}{ Family } & \multirow[t]{2}{*}{$n$} & \multicolumn{11}{|c|}{ Frequency of incidence of petiole lesions } & \multirow[t]{2}{*}{ Mean \pm SE } \\
\hline & & & 0 & 0.1 & 0.2 & 0.3 & 0.4 & 0.5 & 0.6 & 0.7 & 0.8 & 0.9 & 1.0 & \\
\hline Latham & P1 & 18 & 17 & 33 & 33 & 17 & 0 & 0 & 0 & 0 & 0 & 0 & 0 & $0.15 \pm 0.02$ \\
\hline Titan & P2 & 18 & 0 & 0 & 0 & 0 & 0 & 17 & 0 & 0 & 17 & 11 & 56 & $0.86 \pm 0.04$ \\
\hline NY00-34 & P3 & 18 & 17 & 44 & 28 & 11 & 0 & 0 & 0 & 0 & 0 & 0 & 0 & $0.13 \pm 0.02$ \\
\hline Latham $\times$ Titan & $\mathrm{F}_{1}$ & 51 & 47 & 0 & 8 & 6 & 10 & 10 & 4 & 0 & 10 & 2 & 4 & $0.28 \pm 0.05$ \\
\hline NY00-34 × NY00-34 & $\mathrm{F}_{2}$ & 80 & 26 & 15 & 7 & 16 & 5 & 4 & 7 & 3 & 1 & 0 & 15 & $0.33 \pm 0.04$ \\
\hline Latham $\times$ NY00-34 & $\mathrm{B}_{1}$ & 50 & 0 & 22 & 26 & 28 & 16 & 6 & 2 & 0 & 0 & 0 & 0 & $0.25 \pm 0.02$ \\
\hline Titan $\times$ NY00-34 & $\mathrm{B}_{2}$ & 159 & 15 & 9 & 4 & 9 & 7 & 10 & 7 & 6 & 7 & 7 & 18 & $0.50 \pm 0.03$ \\
\hline Titan $\times$ Titan & $\mathrm{S}_{2}$ & 30 & 0 & 3 & 0 & 0 & 0 & 10 & 0 & 0 & 17 & 3 & 67 & $0.88 \pm 0.04$ \\
\hline
\end{tabular}

variance. For this trait the joint scaling test revealed that an additive-dominance model explains most of the variability observed without significant interactions $\left[\chi^{2} \quad(d f=3)=\right.$ 6.145, $P>0.1]$. Narrow and broad sense heritability were estimated to be $h^{2}=0.14$ and $H^{2}=0.95$, respectively. Estimates of components of genetic variance for stem lesion length and root regeneration score were not made due to the lack of parental variances (i.e., the resistant parent scored 0 for stem lesion length, and the susceptible parent scored 0 for root regeneration score).

When the plant disease index data was used to force the classification of individuals into resistant and susceptible classes, the best-fit genetic model for resistance contained two dominant genes (Fig. 1). Deviation from the expected segregation ratios was observed only in the $\mathrm{B}_{1}$ generation (Table 1).

Two parental linkage maps (one utilizing markers originating from NY 00-34 and one with markers from 'Titan') were constructed (Fig. 2). The NY 00-34 map contained seven linkage groups with 138 AFLP, 68 RAPD, and 20 RGAP markers covering $440 \mathrm{cM}$ of genetic distance. Linkage group length ranged from 35 to $86 \mathrm{cM}$. A total of 67 (29\%) markers were removed from this data set due to significant deviations from expected segregation ratios. The 'Titan' map also had seven linkage groups constructed from 153 AFLPs, 47 RAPDs, and 11 RGAPs covering $370 \mathrm{cM}$ of genetic distance. Linkage group length ranged from 26 to $70 \mathrm{cM}$. Nineteen $(8.8 \%)$ markers were skewed and removed from this data set for map construction. Linkage group homology between the maps was identified for four of the seven groups using co-dominant markers (Fig. 2).

A total of 79 resistant gene homology approach (RGA) primer combinations were tested, and 66 (84\%) of the combinations produced good quality amplification products, averaging 6.5 bands/combination. The remaining 13 (16\%) did not visibly amplify DNA. Of the 66 successful combinations, 17 (26\%) produced polymorphic bands among the

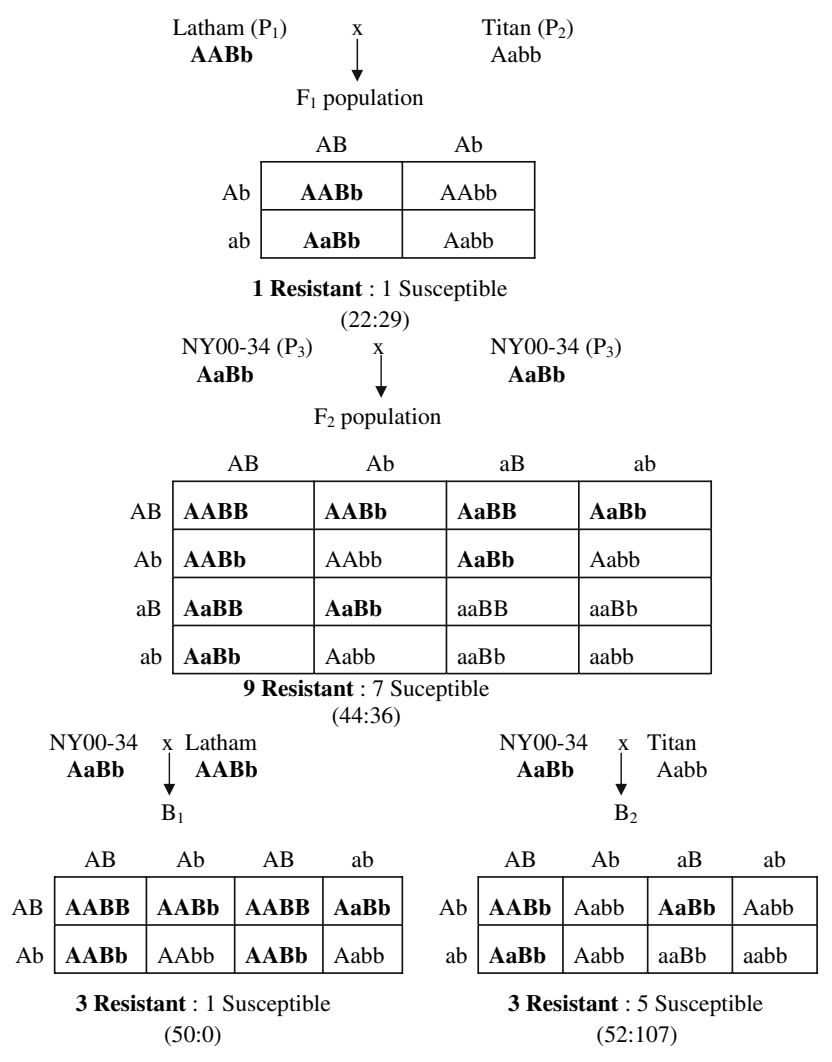

Fig. 1 Proposed genotypes for a dominant two-gene hypothesis for Phytophthora root rot resistance in red raspberry based on best-fit modeling and generational means analysis. Parentheses indicate observed number of segregants in each population

parents with an average of 1.9 polymorphic bands/combination. All of the segregating markers amplified from the RGA primers behaved as dominant markers with most fitting the expected segregation ratios of either $1: 1$ or $3: 1$. An even distribution of RGA markers was observed across most linkage groups.

RAPD markers (ten total) putatively associated with plant disease index scores were identified by analyzing the 
Fig. 2 Genetic linkage maps for NY 00-34 and Titan red raspberry. Linkage groups that could be aligned with heterozygous 3:1 RAPDs and AFLPs are indicated with connecting dotted lines. Vertical bars represent QTL for plant disease index ( $p d i)$, stem lesion length $(s l)$, incidence of petiole lesions $(p l)$, and root regeneration score ( $r r s$ ). RAPD marker nomenclature is made up of the first letters designating primer origin $(B C$ University of British Columbia, $O P$ Operon Technologies). The next three numbers indicate the primer number followed by three numbers indicating the fragment size in base pairs. The AFLP markers were labeled according to the Standard List for AFLP Primer Nomenclature (http:// wheat.pw.usda.gov/ggpages/ keygeneAFLPs.html), e.g., EcoRI+AT/Mse I GTC is labeled E14M76. The marker sizes are given in base pairs. For example, marker EcoRI $+\mathrm{CC} /$ $M s e \mathrm{I}+\mathrm{CTA}$ with a size of $366 \mathrm{bp}$ is labeled as E16M59_366

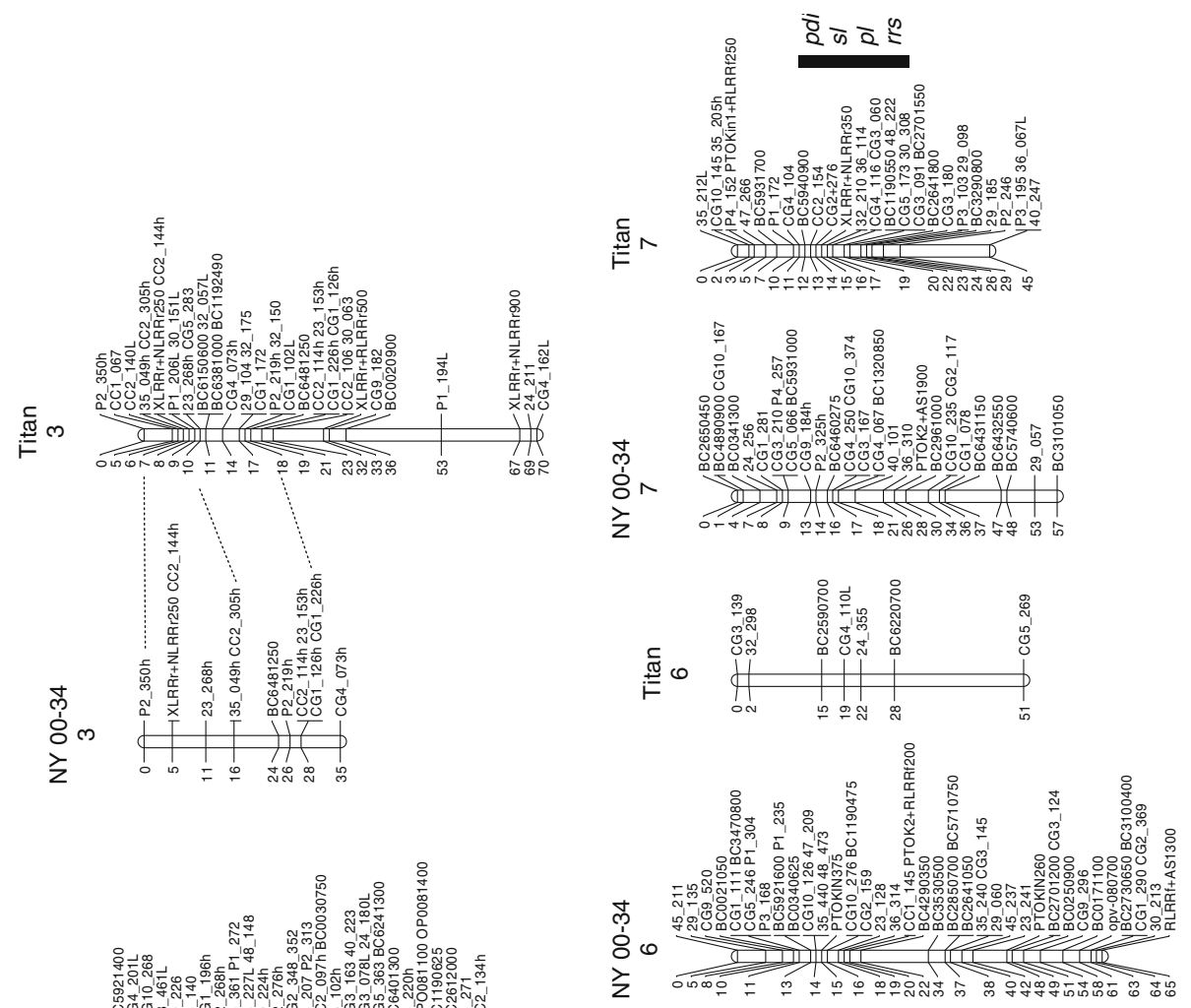

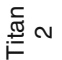

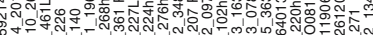

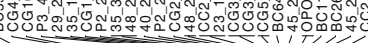

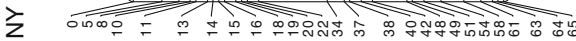
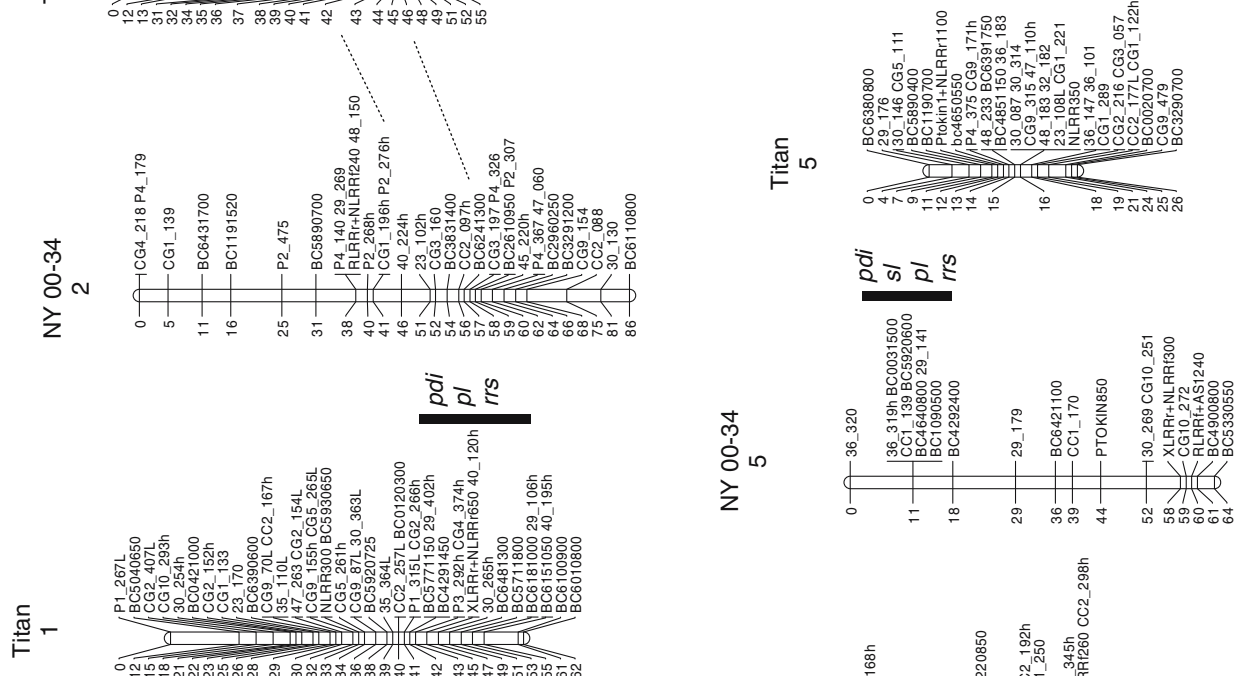

距
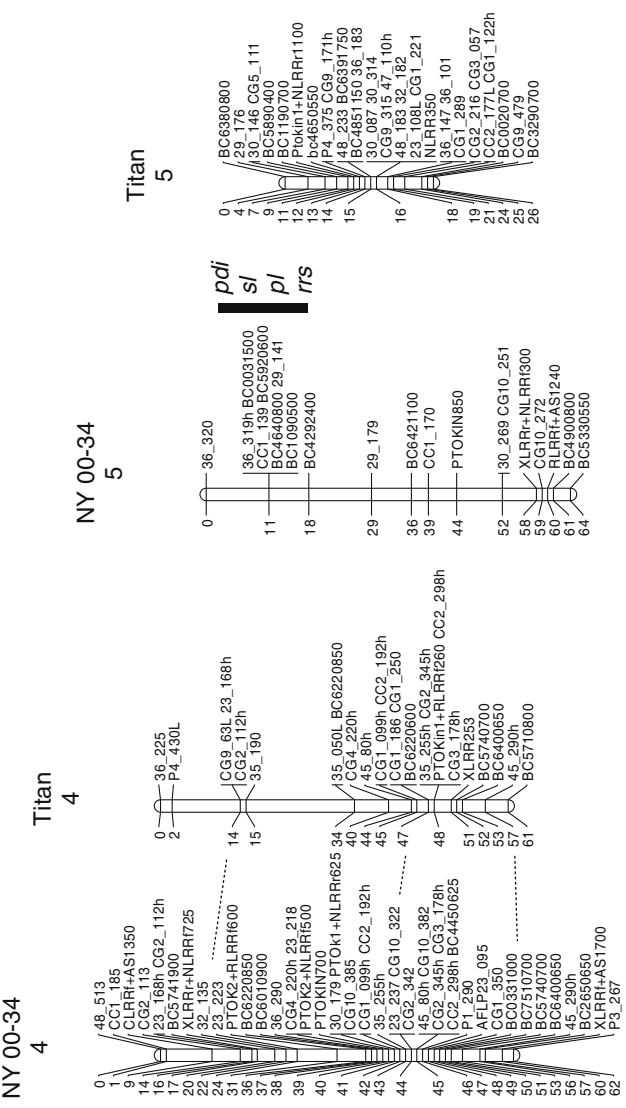
Table 9 RAPD primer and fragment size (base pairs) linked to Phytophthora root rot resistance in red raspberry as determined by plant disease index score and identified by analysis of the distributional extremes of the $\mathrm{B}_{2}$ population

\begin{tabular}{|c|c|c|c|c|}
\hline \multirow[t]{2}{*}{ Primer } & \multicolumn{2}{|c|}{ Fragment } & \multirow{2}{*}{$\begin{array}{l}\text { Linkage } \\
\text { group } \\
\text { (NY 00-34/Titan) }\end{array}$} & \multirow{2}{*}{$\begin{array}{l}\text { Mean pdi score } \\
\text { for marker } \\
\text { present/absent }^{c}\end{array}$} \\
\hline & $\operatorname{Size}^{\mathrm{a}}$ & Origin $^{\mathrm{b}}$ & & \\
\hline ВC003 & 1,500 & NY 00-34 & 5 & $1.86 / 4 * *$ \\
\hline BC109 & 500 & NY 00-34 & 5 & $1.33 / 4.08 * *$ \\
\hline BC592 & 600 & NY 00-34 & 5 & $1.5 / 3.9 * * *$ \\
\hline BC464 & 800 & NY 00-34 & 5 & $1.5 / 3.9 * * *$ \\
\hline BC571 & 1,800 & NY 00-34 & 1 & $4.33 / 2.11 * *$ \\
\hline BC429 & 1,450 & Both & $1 / 1$ & $4.22 / 2.11 * *$ \\
\hline BC437 & 850 & Both & Skewed & $4.22 / 2.11 * *$ \\
\hline BC577 & 1,150 & Both & $1 / 1$ & $4.25 / 2.4^{*}$ \\
\hline BC610 & 900 & Both & $1 / 1$ & $4 / 2.25 *$ \\
\hline BC648 & 1,300 & Both & $1 / 1$ & $4.63 / 2.1 * *$ \\
\hline
\end{tabular}

${ }^{a}$ Fragment size in nucleotides estimated from gel with $1 \mathrm{~kb}$ ladder

${ }^{b}$ Parental origin of linked marker (both indicates a heterozygous marker segregating $3: 1$ )

${ }^{c}$ Significance of difference determined by $t$-test

$* P=0.05$

$* * P=0.01$

$* * * P=0.001$

distributional extremes of the $\mathrm{B}_{2}$ population (Table 9). Markers associated with resistance originated from 'Latham.' Conversely, all markers associated with susceptibility were heterozygous among the parents and segregated 3:1 in the population. No markers of strictly 'Titan' origin were found to be associated with either resistance or susceptibility. The linked RAPD markers clustered on two linkage groups of NY 00-34 (groups 1 and 5) and to linkage group 1 on the 'Titan' map (Fig. 2).

QTL analysis was performed on both parental maps for each of the disease assessment criteria. QTL were identified on linkage group 1 of both parental maps for the plant disease index, the incidence of petiole lesions and the root regeneration score. This QTL corresponded to one of the regions of BSA marker clustering. On linkage group 1 of NY 00-34, the QTL accounted for $~ 30,61$, and $25 \%$ of the phenotypic variation for plant disease index, incidence of petiole lesions and root regeneration score, respectively. On linkage group 1 of the 'Titan' map, the QTL accounted for $\sim 26,33$, and $29 \%$ of the phenotypic variation for plant disease index, incidence of petiole lesions, and root regeneration score, respectively.

QTL for plant disease index, stem lesion size, incidence of petiole lesions, and root regeneration score were found to be located around the other BSA marker cluster on linkage group 5 of NY 00-34 and accounted for $\sim 28,10,28$, and $15 \%$, respectively, of the observed variation. A second region on the 'Titan' map (group 7) yielded significant QTL for plant disease index, stem lesion size, incidence of petiole lesions and root regeneration score and accounted for $\sim 15,18,14$, and $16 \%$, respectively, of the observed variation.

\section{Discussion}

Overall control of resistance to root rot caused by $P$. fragariae var. rubi is neither monogenic nor extensively quantitative based on the observed segregation in these red raspberry populations. The segregation of plant disease index scores over all populations revealed that an additivedominance model could not account adequately for the variation present for root rot resistance. While additive variance was the largest portion of the observed variance, accounting for high heritability estimates for plant disease index, other interactions were also significant. The complex nature of symptoms in this disease can account for this mixed inheritance model. This is demonstrated by the data on incidence of petiole lesions, which was calculated to follow a dominance model with a low narrow sense heritability. Inferences can be made from the segregation observed in the $F_{1}$ and $B_{2}$ population that depending on the trait measured, dominance effects and/or heterozygosity within the parents have variable importance based on the genetic make up of the population studied.

This data also suggests that NY00-34 is more heterozygous for resistance than 'Latham' and that more than one gene is conditioning resistance. Goodness of fit tests using forced classification of resistance show that a dominant two-gene model accounts for most of the variability in overall resistance.

The $\mathrm{B}_{1}$ population did not fit our two-gene model due to skewing toward resistance. This population was very difficult to establish in the greenhouse and the hydroponic screening system due to powdery mildew to which 'Latham' is extremely susceptible. This problem was not encountered in the other populations. Six individuals in the $\mathrm{B}_{1}$ population were classified as intermediate for plant disease index (score of 3), which was not observed in the clonal test of 'Latham' and NY00-34 and would not expected in this population if the dominant two-gene model were correct. While there is no evidence of a direct genetic linkage between susceptibility to powdery mildew and susceptibility to PRR, it is conceivable that a physiological linkage exists. Vigor plays a difficult to quantify role in resistance to many diseases. Many diseases infect and spread in rapidly growing tissues that provide more possible infection sites. While developing the hydroponic system it was observed that with little root growth there were fewer 
PRR symptoms even in known susceptible genotypes. Such plants entered a semi-dormant state and failed to either grow or display disease progression (Pattison et al. 2004).

Severe infection with powdery mildew also produces a general lack of vigor with reduced root growth in the hydroponic system. There were six individuals in the $\mathrm{B}_{1}$ population with a plant disease index rating of 3 . There were none in either parent clonal test and none would be expected in the $\mathrm{B}_{1}$ population if the two-gene model was accurate, but 12 susceptible individuals (four or five rating) would be expected. The six intermediate genotypes all had low root regeneration scores (1) and a high incidence of petiole lesions (40-60\%) and therefore, we believe they are susceptible. Classifying those six (44:6) as susceptible gives a chi-square of 3.84 and thus $P>0.05$, which is much more likely due to chance with the small population tested.

However, other genetic factors cannot be ruled out with the data observed especially considering the results of the generational means analysis. The experimental design and resulting genetic model proposed in this study can only adequately account for major sources of genetic variation and given the complexity of plant pathogen interactions it is likely that other minor genes are involved. In spite of the $\mathrm{B}_{1}$ population not fitting our genetic model without reclassification of the intermediate response, the presence of large amounts of additive, and interaction genetic variation observed in the other populations suggests that the recovery of high percentages of resistant individuals is possible using either recurrent selection or backcross procedures.

As was observed by Nestby and Heiberg (1995) with both positive and negative specific combining abilities in multiple half-sibling families, high levels of heterozygosity in the parents can provide conflicting inheritance patterns. This combined with suggested oligogenic control of resistance to PRR makes inheritance of resistance hard to predict. The subterranean habit of the disease and the complex symptom expression are also complicating factors when trying to study this plant-pathogen interaction because monitoring the effectiveness of inoculation procedures and the progression of root symptoms in soil-based assays is difficult. The hydroponic system makes it possible to score the disease reaction in the pathogen's target tissue repeatedly in a non-destructive manner (Pattison et al. 2004).

Strong correlations between the plant disease index, root regeneration score and incidence of petiole lesions have been reported earlier (Pattison and Weber 2005). In the current work, we have observed molecular evidence for this based on the co-localization of the identified QTL for those traits on the molecular genetic linkage map. QTL for stem lesion size, which was shown to possess a weaker correlation with plant disease index, was present on only two of the four declared QTL regions on both parental maps. Therefore, if the goal of selection were for absolute resis- tance then the qualitative criteria would be appropriate. Alternatively, if population improvement with recurrent selection is the objective, quantitative data such as incidence of petiole lesions may help to identify those individuals in breeding populations that possess intermediate levels of resistance with more confidence.

Even with all the challenges in evaluating resistance to PRR, the results of this study favor the Nestby and Heiberg (1995) conclusion that variation for resistance to PRR in red raspberry has both significant non-additive and additive components. In our study, the importance of the two genetic components varied depending on how resistance was assessed. The complex expression of secondary symptoms (leaf chlorosis, petiole lesions, necrosis, and scorching) makes an additive model more likely to account for the observed variability for the plant disease index, which evaluates the whole plant response to infection. Multiple genetic factors likely influence traits such as the environmental stress response (i.e., nutrient and water stress) and their segregation in these populations may be responsible for the predominating additive model proposed. However, our data show that by evaluating individual symptoms of PRR, most of the variability in PRR resistance can be explained by dominance effects in a two-gene system.

A genetic linkage map of red raspberry was recently constructed using AFLPs, SSRs, and EST-SSR markers using a pseudo-testcross mapping strategy (Graham et al. 2004). Our mapping strategy varied in that a segregating $B_{2}$ population was used to generate two linkage maps, one for each parent, and used dominant markers. Our genetic map was approximately half the size of the published map of Graham et al. (2004) and therefore, likely does not have full genome coverage.

The RGA used in this study did not investigate the homology of amplified fragments to known resistance genes. Rather, the goal at this stage was to generate markers segregating in a Mendelian fashion from sequence specific primers designed from resistance genes, observe map placement and test for association with the resistant phenotypes. Amplification products were easily separated using Metaphor agarose gels, which allowed for efficient marker generation. Few RGAP markers were found in close proximity to the identified QTL. This is the first documentation of using this method as strictly a marker generation system for molecular mapping in red raspberry.

The two genetic analyses support the conclusion that resistance to PRR is conditioned by major genes in these red raspberry populations. Our experimental design for molecular mapping and subsequent QTL analysis did not allow for the fine scale dissection and identification of minor genes influencing resistance as the population size was appropriate only for identifying regions that produced modest to large effects on the phenotype. Breeding methods 
best suited for utilizing this type of genetic variation fit well into contemporary raspberry programs, which already use recurrent selection and modified backcrossing for maximizing the recovery of resistant progeny. Future work will focus on producing sequence specific markers in close proximity to the identified QTL to test the robustness of the association with the resistant phenotype in the cultivated germplasm of red raspberry.

Acknowledgments This project was funded in part by the National Research Initiative of the United States Department of Agriculture Cooperative State Research, Education and Extension Service (NRI, USDA-CSREES), grant number \#NYG-632526.

\section{References}

Allard RW (1960) Principles of plant breeding. Wiley, New York

Barritt BH, Crandall PC, Bristow PR (1979) Breeding for root rot resistance in red raspberry. J Am Soc Hortic Sci 104:92-94

Barritt BH, Crandall PC, Bristow PR (1981) Red raspberry clones resistant to root rot. Fruit Var J 35:60-62

Bristow PR, Daubeny HA, Sjulin TM, Pepin HS, Nestby R, Windom GE (1988) Evaluation of Rubus germplasm for reaction to root rot caused by Phytophthora erythroseptica. J Am Soc Hortic Sci 113:588-591

Cai Q, Guy CL, Moore GA (1994) Extension of the linkage map in Citrus using random amplified polymorphic DNA (RAPD) markers and RFLP mapping of cold-acclimation-responsive loci. Theor Appl Genet 89:606-614

Cavalli LL (1952) An analysis of linkage of quantitative inheritance. In: Reeve ECR, Waddington CH (eds) Quantitative inheritance. HM Stat Off, London, pp 135-144

Chen XM, Line RF, Leung H (1998) Genome scanning for resistance gene analogs in rice, barley, and wheat by high-resolution electrophoresis. Theor Appl Genet 97:345-355

Collins NC, Webb CA, Seah S, Ellis JG, Hulbert SH, Pryor A (1998) The isolation and mapping of disease resistance gene analogs in maize. Mol Plant Microbe Interact 11:968-976

Daubeny HA, Anderson AK (1993) Achievements and prospects-the British Columbia red raspberry breeding program. Acta Hortic 352:285-293

Deng Z, Huang S, Ling P, Chen C, Yu C, Weber CA, Moore GA, Gmitter FG Jr (2000) Cloning and characterization of NBS-LRR class resistance gene candidate sequences in citrus. Theor Appl Genet 101:814-822

Di Gaspero G, Cipriani G (2002) Resistance gene analogs are candidate markers for disease resistance genes in grape (Vitis spp.). Theor Appl Genet 106:163-172

Di Gaspero G, Cipriani G (2003) Nucleotide binding site/leucine-rich repeats, Pto-like and receptor-like kinases related to disease resistance in grapevine. Mol Genet Genomics 5:612-623

Graham J, Smith K, MacKenzie K, Jorgenson L, Hackett C, Powell W (2004) The construction of a genetic linkage map of red raspberry (Rubus idaeus subsp. idaeus) based on AFLPs, genomic SSR and EST-SSR markers. Theor Appl Genet 109:740-749

Heiberg N (1995) Control of root rot of red raspberries caused by Phytophthora fragariae var. rubi. Plant Pathol 44:153-159

Kanazin V, Marek LF, Shoemaker RC (1996) Resistance gene analogs are conserved and clustered in soybean. Proc Natl Acad Sci USA 93:11746-11750

Knight VH (1991) Use of the salmonberry Rubus spectabilis Pursh. in red raspberry breeding. J Hortic Sci 66:575-582
Levesque CA, Daubeny HA (1999) Variation in reaction to Phytophthora fragariae var. rubi in raspberry genotypes. Acta Hortic 505:231-235

Leister D, Ballova A, Salamini F, Gebhardt C (1996) A PCR-based approach for isolating pathogen resistance genes from potato with a potential wide application in plants. Nat Genet 14:421-429

Liebhard R, Koller B, Gianfranceschi L, Gessler C (2003) Creating a saturated reference map for the apple (Malus x domestica Borkh.) genome. Theor Appl Genet 106:1497-1508

Lodhi MA, Ye G-N, Weeden NF, Reisch BI (1994) A simple and efficient method for DNA extraction from grapevine cultivars and $\mathrm{Vi}$ tis species and Ampelopsis. Plant Mol Biol Rep 12:6-13

Lopez CE, Zuluaga AP, Cooke R, Delseny M, Tohme J, Verdier V (2003) Isolation of Resistance Gene Candidates (RGCs) and characterization of an RGC cluster in cassava. Mol Genet Genomics 5:658-671

Maloney KE, Wilcox WF, Sanford JC (1993) Effects of raised beds and metalaxyl for control of Phytophthora root rot of raspberry. HortScience 28:1106-1108

Maloney KE (2001) Examination of soil amendments, chemical sprays and screening as potential control methods for Phytophthora root rot in red raspberry (Rubus idaeus L.). MS. Thesis, Cornell University, Ithaca, NY

Mather K, Jinks JL (1982) Biometrical genetics, 3rd edn. Chapman and Hall, London

Nestby R, Heiberg N (1995) Genetic variation for resistance to Phytophthora fragariae var. rubi in red raspberries. Euphytica 81:143-149

Ng TJ (1990) Generation means analysis by microcomputer. HortScience 25:363

Pattison JA, Weber CA (2005) Evaluation of red raspberry cultivars for resistance to Phytophthora root rot. J Am Pom Soc 59:50-56

Pattison JA, Wilcox WF, Weber CA (2004) Assessing the resistance of red raspberry (Rubus idaeus L.) genotypes to Phytophthora fragariae var. rubi in hydroponic culture. HortScience 39:1553-1556

Sargent D, Davis Y, Tobutt K, Wilkinson M, Battey N, Simpson D (2004) A genetic linkage map of microsatellite, gene-specific and morphological markers in diploid Fragaria. Theor Appl Genet 109:1385-1391

Shen KA, Meyers BC, Islam-Faridi M-N, Chin DB, Stelly DM, Michelmore RW (1998) Resistance gene candidates identified by PCR with degenerate oligonucleotide primers map to clusters of resistance genes in lettuce. Mol Plant Microbe Interact 8:815-823

Strickberger MW (1985) Genetics, 3rd edn. Macmillan Publishing, New York

Van Oijen JW, Voorips RE (2001) JoinMap 3.0®, software for the calculation of genetic maps. Plant Research International, Wageningen, The Netherlands

Van Oijen JW, Boer MP, Jansen RC, Maliepaard C (2002) Software for the calculation of QTL positions on genetic maps. Plant Research International, Wageningen, The Netherlands

Vos P, Hogers R, Bleeker M, Reijans M, Vandelee T, Hornes M, Frijters A, Pot J, Peleman J, Kuiper M, Zabeau M (1995) AFLP: a new technique for DNA fingerprinting. Nucleic Acids Res 23:4407-4414

Warner JN (1952) A method for estimating narrow-sense heritability. Agron J 44:427-430

Wilcox WF (1989) Identity, virulence and isolation frequency of seven Phytophthora spp. causing root rot of raspberry in New York State. Phytopathology 79:93-101

Wilcox WF, Scott PH, Hamm PB, Kennedy DM, Duncan JM, Brasier CM, Hansen EM (1993) Identity of a Phytophthora species attacking raspberry in Europe and North America. Mycol Res 97:817-831

Wilcox WF, Pritts MP, Kelly MJ (1999) Integrated control of Phytophthora root rot of red raspberry. Plant Dis 83:1149-1154 
Wilcox WF, Latorre BA (2002) Identities and geographic distributions of Phytophthora spp. causing root rot of red raspberry in Chile. Plant Dis 86:1357-1362
Yu YG, Buss GR, Maroof MAS (1996) Isolation of a super family of candidate disease resistance genes in soybean based on a conserved nucleotide-binding site. Proc Natl Acad Sci USA 93:11751-11756 